Нами, как и рядом других авторов, выявлено, что при переходе на одногодичную службу по призыву произошло увеличение заболеваемости личного состава по всем заболеваниям. С переходом на одногодичную службу наблюдается рост заболеваемости среди военнослужащих по призыву. На заболеваемость болезнями органов дыхания и внебольничной пневмонии оказывают влияния погодные условия, а также условия размещения личного состава в казарме. При увеличении внеплановой служебной нагрузки отмечается рост общей заболеваемости и заболеваемости болезнями органов дыхания среди военнослужащих. Выявлена группа риска по болезням органов дыхания. На уровень заболеваемости военнослужащих по призыву влияет ресурсное обеспечение медицинской службы, в частности число развернутых коек в медицинском пункте. Увеличение перед эпидемически неблагоприятным периодом до 75 числа коек в медицинском пункте из расчета на 1000 военнослужащих позволяет снизить заболеваемость внебольничной пневмонией.

$$
\text { *** }
$$

1. Roitberg G.E., Dorosh Z.V., Sharkhun O.O. A new method for screening diagnosis of insulin resistance // Bulletin of Experimental Biology and Medicine. 2015. T. 158. № 3. C. 397-400.

2. Белевитин А.Б., Фесюн А.Д., Божченко А.А., Сухонос Ю.А., Федосеев В.М. Медицинская реабилитация в системе медицинского обеспечения силовых структур Российской Федерации: методологические, исторические и организационные аспекты // Медицина катастроф. 2011. № 1. С. 2628.

3. Белевитин А.Б., Фесюн А.Д., Божченко А.А., Сухонос Ю.А., Федосеев В.М. Современные взгляды на медицинскую реабилитацию лиц опасных профессий // Медицина катастроф. 2011. № 2. С. 14-17.

4. Датий А.В., Селиванов С.Б., Панфилов Н.В. Опыт создания информационно-аналитической базы социально-гигиенического мониторинга в системе Минюста России // Гигиена и санитария. 2004. № 5. C. 23.

5. Датий А.В., Фесюн А.Д., Власенко А.В., Никифорова А.А. Портрет больных гипертонией // Центральный научный вестник. 2017. Т. 2. № 15 (32). С. 3.

6. Ройтберг Г.Е., Кондратова Н.В. Методические подходы к оценке культуры безопасности в медицинской организации // В мире научных открытий. 2016. № 3 (75). С. 57-71.

7. Ройтберг Г.Е., Кондратова Н.В., Галанина Е.В. Возможности повышения безопасности пациента в медицинской организации // Успехи современной науки. 2016. Т. 1. №4.С.135-142.

8. Сабанин Ю.В., Фесюн А.Д., Кореняк Р.Ю. Основные принципы существующей системы медикопсихологической реабилитации военнослужащих внутренних войск МВД России и дальнейшее направление ее совершенствования // Медицинский вестник МВД. 2011. № 1 (50). С. 2-6.

\title{
Цех О.М. \\ Возрастная динамика астенического синдрома при НР-ассоциированном хроническом гастродуодените
}

ООО «Американская медицинская клиника» (Россия, Санкт-Петербург)

doi: $10.18411 / \mathrm{j}-30-09-2017-14$

idsp: 000001:lj-30-09-2017-14

\section{Аннотация}

Представлены результаты опроса и обследования 147 больных с морфологически верифицированным НР-ассоциированным хроническим гастродуоденитом: детей, подростков, взрослых и пожилых. Показано, что наиболее выражен астенический синдром у подростков и пожилых, что связано с возрастными особенностями и сопутствующей патологией.

Ключевые слова: астения, возрастные особенности, НР-ассоциированный хронический гастродуоденит

Астенический синдром - состояние, характеризующееся повышенной утомляемостью, частой сменой настроения, раздражительностью слабостью, 
гиперестезией, слезливостью, вегетативными нарушениями и расстройствами сна [1]. Он является частью клинической картины хронических заболеваний внутренних органов [2]. Значительное количество астенических жалоб отмечается при хроническом гастродуодените [3, 4], что обусловлено целым рядом причин, среди которых на 1 месте коморбидная патология [5]: лямблиоз и хеликобактериоз [6, 7, 8], анемия [9], заболевания щитовидной железы $[10,11,12]$, ожирение [13], заболевания соединительной ткани [14, $15,16]$ и другие сопутствующие заболевания. С помощью метода масспектрометрии микробных маркеров [17] выявлены существенные изменения кишечной микробиоты в различные фазы течения хронического гастродуоденита $[18,19]$ и найдены корреляционные зависимости между астеническими жалобами и персистированием в кишечнике определенных штаммов. Влияют на выраженность астенического синдрома питание пациентов [20], изменение микроэлементного статуса организма и полигиповитаминозы [21]. Разная активность нейроэндокринных клеток в слизистой оболочке двенадцатиперстной кишки может обуславливать разную выраженность астенического синдрома при гастродуоденитах различной этиологии [22]. В то же время возрастные особенности астенического синдрома при НР-ассоциированном хроническом гастродуодените изучены недостаточно.

Цель исследования: описать возрастную динамику астенического синдрома у больных с НР-ассоциированным хроническим гастродуоденитом.

Материалы и методы. Изучение частоты и выраженности астенического синдрома в разных возрастных группах проведено методом расспроса у 147 пациентов, страдающих морфологически верифицированным НР-ассоциированном хроническим гастродуоденитом. Все обследованные были разделены на четыре группы: группу 1 -

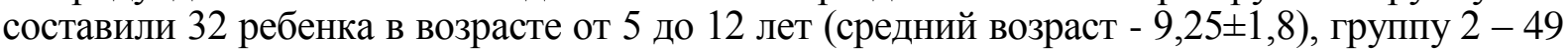
подростков от 13 до 17 лет (средний возраст - 14,82 $\pm 1,26$ ), группу 3 - 40 взрослых от 18

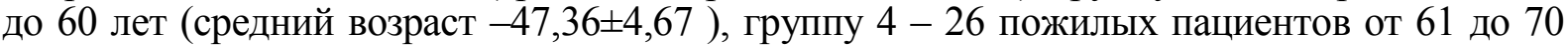
лет (средний возраст $-67,5 \pm 1,29)$. Мужской пол преобладал только в группе подростков $(\mathrm{p}<0,01)$. Гистологическое обследование биоптатов слизистой оболочки желудка и двенадцатиперстной кишки, полученных в результате ФГДС, проводилось на кафедре патологической анатомии СЗГМУ им И.И.Мечникова. Хеликобактериоз подтверждался комплексом методов: гистологически и дыхательным уреазным методом с помощью прибора Хеликосенс $[23,24]$. Статистический анализ результатов проводили с помощью программных средств и пакета Statistica 6.0 for Windows 9.0. В исследовании использовались пакеты прикладных программ: SPSS 14 версии для статистического анализа, MS Office Excel 2003 для организации и формирования матрицы данных, подготовки графиков и диаграмм.

Результаты. Среди астеноневротических жалоб у обследованных пациентов чаще всего встречалась повышенная утомляемость, причем ее частота коррелировала с возрастом ( $\mathrm{r}=0,7, \mathrm{p}<0,05)$. Отмечалась положительная корреляционная зависимость между нарушением внимания и возрастом $(\mathrm{r}=0,81, \mathrm{p}<0,05)$. В группе пожилых чаще были жалобы на головные боли, по сравнению с другими группами (таблица 1).

Таблица 1

Астеноневротические жалобы у больных хроническим дуоденитом в разных возрастных группах исследования (абсолютное число /\%).

\begin{tabular}{|c|c|c|c|c|c|}
\hline \multirow{2}{*}{ Группа } & 1 & 2 & 3 & 4 & \multirow{2}{*}{ Р } \\
\cline { 2 - 5 } Признак & Дети & Подростки & Взрослые & Пожилые & \\
\cline { 2 - 5 } & $\mathrm{n}=32$ & $\mathrm{n}=49$ & $\mathrm{n}=40$ & $\mathrm{n}=26$ & \\
\hline & & & & & $\mathrm{p}_{1,2}>0,05$ \\
Повышенная утомляемость & \multirow{2}{*}{$18 / 56,25 \%$} & $32 / 65,31 \%$ & $33 / 82,5 \%$ & $24 / 92,31 \%$ & $\mathrm{p}_{1,3}<0,05$ \\
$\mathrm{p}_{1,4}<0,01$ \\
& & & & & $\mathrm{p}_{2,3}>0,05$ \\
& & & & & $\mathrm{p}_{2,4}<0,05$ \\
$\mathrm{p}_{3,4}<0,001$ \\
\hline
\end{tabular}




\begin{tabular}{|c|c|c|c|c|c|}
\hline & & & & & $\mathrm{p}_{3,4}<0,001$ \\
\hline Раздражительность, плаксивость & $10 / 31,25$ & $14 / 28,57 \%$ & $7 / 17,5 \%$ & $5 / 19,23 \%$ & $\mathrm{p}>0,05$ \\
\hline Нарушение внимания & $4 / 12,5 \%$ & $4 / 8,16 \%$ & $12 / 30 \%$ & $21 / 80,76 \%$ & $\begin{aligned} \mathrm{p}_{1,2} & >0,05 \\
\mathrm{p}_{1,3} & >0,05 \\
\mathrm{p}_{1,4} & <0,001 \\
\mathrm{p}_{2,3} & <0,01 \\
\mathrm{p}_{2,4} & <0,001 \\
\mathrm{p}_{3,4} & <0,001\end{aligned}$ \\
\hline
\end{tabular}

Столь высокий процент неспецифических жалоб у пожилых вероятнее всего, связан с наличием сопутствующих заболеваний сердца и сосудов. Хочется отметить, что у подростков тоже отмечались головные боли чаще, чем у взрослых, что связано с особенностями вегетативной нервной системы в подростковом возрасте [25] и с более высокой частотой вегетососудистой дистонии и заболеваний ЛОР-органов в этой возрастной группе (таблица 2).

Таблииа 2

Структура сопутствуюших хронических заболеваний у больных разного возраста с НР-ассочиированным ХГД (абс. число /\%).

\begin{tabular}{|c|c|c|c|c|c|}
\hline \multirow{3}{*}{$\begin{array}{l}\text { Группы } \\
\text { Признак }\end{array}$} & 1 & 2 & 3 & 4 & \multirow{3}{*}{$\mathrm{P}$} \\
\hline & Дети & Подростки & Взрослые & Пожилые & \\
\hline & $\mathrm{n}=32$ & $\mathrm{n}=49$ & $\mathrm{n}=40$ & $n=26$ & \\
\hline $\begin{array}{c}\text { Аллергические } \\
\text { заболевания }\end{array}$ & $10 / 31,25 \%$ & $18 / 36,73 \%$ & $9 / 22,5 \%$ & $5 / 19,23 \%$ & $\mathrm{p}>0,05$ \\
\hline $\begin{array}{c}\text { Заболевания } \\
\text { почек }\end{array}$ & $9 / 28,1 \%$ & $13 / 26,5 \%$ & $12 / 30 \%$ & $7 / 26,9 \%$ & $\mathrm{p}>0,05$ \\
\hline $\begin{array}{c}\text { Заболевания } \\
\text { ЛОР-органов }\end{array}$ & $15 / 31,25 \%$ & $19 / 38,77 \%$ & $5 / 12,5 \%$ & $3 / 11,5 \%$ & $\begin{aligned} \mathrm{p}_{1,2} & >0,05 \\
\mathrm{p}_{1,3} & <0,001 \\
\mathrm{p}_{1,4} & <0,01 \\
\mathrm{p}_{2,3} & <0,001 \\
\mathrm{p}_{2,4} & <0,05 \\
\mathrm{p}_{3,4} & >0,05\end{aligned}$ \\
\hline $\begin{array}{c}\text { Гипертоническа } \\
\text { я болезнь ГБ }\end{array}$ & 0 & 0 & $18 / 45 \%$ & $26 / 100 \%$ & $\begin{array}{l}\mathrm{p}_{1,2}>0,05 \\
\mathrm{p}_{1,3}<0,01 \\
\mathrm{p}_{1,4}<0,01 \\
\mathrm{p}_{2,3}<0,01\end{array}$ \\
\hline Анемии & $3 / 9,3 \%$ & $7 / 14,28 \%$ & $10 / 25 \%$ & $11 / 42,3 \%$ & $\begin{array}{l}\mathrm{p}_{1,2}>0,05 \\
\mathrm{p}_{1,3}<0,01 \\
\mathrm{p}_{1,4}<0,01 \\
\mathrm{p}_{2,3}>0,05 \\
\mathrm{p}_{2,4}<0,01 \\
\mathrm{p}_{3,4}>0,05\end{array}$ \\
\hline $\begin{array}{c}\text { Вегето- } \\
\text { сосудистая } \\
\text { дистония ВСД }\end{array}$ & $9 / 28,12 \%$ & $22 / 44,9 \%$ & $5 / 12,5 \%$ & $2 / 7,69 \%$ & $\begin{array}{c}\mathrm{p}_{1,2}>0,05 \\
\mathrm{p}_{1,3}>0,05 \\
\mathrm{p}_{1,4}<0,001 \\
\mathrm{p}_{2,3}<0,001 \\
\mathrm{p}_{2,4}<0,001 \\
\mathrm{p}_{3,4}>0,05\end{array}$ \\
\hline $\begin{array}{c}\text { Заболевания } \\
\text { ЦНС }\end{array}$ & $3 / 9,37 \%$ & $5 / 10,2 \%$ & $7 / 17,5 \%$ & $7 / 26,9 \%$ & $\begin{array}{l}\mathrm{p}_{1,2}>0,05 \\
\mathrm{p}_{1,3}>0,05 \\
\mathrm{p}_{1,4}<0,01 \\
\mathrm{p}_{2,3}>0,05 \\
\mathrm{p}_{2,4}>0,05 \\
\mathrm{p}_{3,4}>0,05\end{array}$ \\
\hline
\end{tabular}

Патология ЛОР органов чаще была у детей и подростков, чем у взрослых и пожилых. Такие заболеваний как гипертоническая болезнь, анемии, были характерны для пожилых, по сравнению с другими группами. Выявлена положительная корреляционная связь между возрастом и частотой заболевания ЦНС $(\mathrm{r}=0,82 \mathrm{p}<0,05)$. ВСД чаще выявлялась у подростков по сравнению с взрослыми. 
Заключение. Астенические жалобы при НР-ассоциированном хроническом гастродуодените у подростков более выражены, чем у взрослых, что может быть связано с анатомо-физиологическими особенностями этого возрастного периода и большей частотой сопутствующей патологии Лор-органов и вегетативной нервной системы. Вторым возрастным периодом, когда возрастает частота астении является пожилой возраст, что связано с большим числом коморбидных заболеваний.

$$
\text { *** }
$$

1. Вишневский В.И., Мельникова И.Ю., Новикова В.П., Хорошинина Л.П. Основные клинические симптомы и синдромы от педиатрии до гериатрии. Учебное пособие для студентов и врачей / СанктПетербург, 2008.

2. Балукова Е.В., Болдуева С.А., Гурова М.М., Новикова В.П., Оганезова И.А., Сметанников П.Г., Успенский Ю.П., Фоминых Ю.А., Хорошинина Л.П. Астенические расстройства в терапевтической практике. Руководство по диагностике и лечению / Санкт-Петербург, 2011.

3. Гурова М.М., Новикова В.П., Гусева С.П., Дутлова Е.Д.Особенности астенического синдрома у детей с хроническим гастродуоденитом. Вопросы детской диетологии. 2017. Т. 15. № 2. С. 48.

4. Gurova M.M., Romanova T.A., Podsvirova E.V., Novikova V.P.Features of psychosomatic status in adolescents with chronic gastroduodenitis.International Journal of Pharmacy and Technology. .2016. T. 8. № 2. C. $14422-14429$.

5. Гурова М.М., Новикова В.П.Значение индекса коморбидности в оценке особенностей течения хронического гастродуоденита у детей. Вопросы детской диетологии. 2016. Т. 14. № 2. С. 74-75.

6. Бельмер С.В., Бехтерева М.К., Калинина Е.Ю., Новикова В.П., Осмаловская Е.А., Шабалов А.М. Лямблиоз. Учебное пособие для врачей / Под редакцией В. П. Новиковой, М. К. Бехтеревой, С. В. Бельмера. Санкт-Петербург, 2014. (2-е издание, исправленное и дополненное)

7. Новикова В.П., Осмаловская Е.А., Калинина Е.Ю.Хеликобактериоз и лямблиоз при хроническом гастродуодените у детей. РМЖ. 2014. Т. 22. № 20. С. 1448-1451.

8. Авалуева Е.Б., Аничков Н.М., Балукова Е.В., Барышникова Н.В., Белоусова Л.Н., Бубнова Е.А., Гузеева О.В., Калинина Е.Ю., Крулевский В.А., Новикова В.П., Нахимова И.Г., Сидоркин А.О., Смирнова А.С., Суворов А.Н., Успенский Ю.П., Фоминых Ю.А., Цех О.М. Инфекция Helicobacter pylori в клинической практике. Санкт-петербург, 2011.

9. Gurova M., Novikova V.P.Peculiarities of iron deficiency anemia associated with helicobacter pylori infection in children. United European Gastroenterology Journal. 2015. T. 3. № 5S. C. A321.

10. Земскова Е.А., Мельникова И.Ю., Новикова В.П., Нажиганов О.Н. Хронический гастродуоденит у детей с сопутствующим аутоиммунным тиреоидитом. Профилактическая и клиническая медицина. 2013. № 1 (46). С. 32-34.

11. Новикова В.П., Бубнова Е.А.Хронический гастрит и заболевания щитовидной железы у детей. Детская медицина Северо-Запада. 2012; 3(1):75-84.

12. Novikova V.P., Iur'ev V.V., Tkachenko E.I., Strukov E.L., Liubimov I.A., Antonov P.V.Chronic gastritis in children with concomitant diseases of the thyroid gland. Экспериментальная и клиническая гастроэнтерология. 2003. № 7. С. 40-43, 114.

13. Алешина Е.И., Комиссарова М.Ю., Новикова В.П., Калинина Е.Ю. Особенности хронического гастродуоденита у детей с сопутствующим ожирением I-II степени. Врач-аспирант. 2012;51(2.2): 257265.

14. Листопадова А.П., Новикова В.П., Мельникова И.Ю., Петровский А.Н.Клинико-морфологические сопоставления при хроническом гастрите у детей с ювенильным артритом. В сборнике: Актуальные вопросы и перспективы развития медицины. Сборник научных трудов по итогам международной научно-практической конференции. Инновационный центр развития образования и науки. 2014. С. 3436.

15. Листопадова А.П., Новикова В.П., Калинина Н.М., Демченкова О.А., Петровский А.Н.Хронический гастрит (ХГ) у детей на фоне заболеваний соединительной ткани. Экспериментальная и клиническая гастроэнтерология. 2014. № 2 (102). С. 73.

16. Бабак С.В., Бакунин И.Г., Балукова Е.В., Барышникова Н.В., Вербицкий В.Г., Гурова М.М., Егошина В.А., Едемская М.А., Каратеев А.Е., Макарова М.Н., Назаров В.Е., Новикова В.П., Пахомова И.Г., Сандлер Ю.Г., Успенский Ю.П., Фоминых Ю.А., Хорошинина Л.П., Шабров А.В. Поражения органов пищеварения, индуцированные приемом нестероидных противовоспалительных препаратов. СанктПетербург, 2013.

17. Осипов Г.А., Бойко Н.Б., Новикова В.П., Гриневич В.Б., Федосова Н.Ф., Цех О.М., Токарева Е.В., Земскова Е.А.Методика масс-спектрометрии микробных маркеров как способ оценки пристеночной кишечной микробиоты при заболеваниях органов пищеварения. Санкт-Петербург, 2013. 
18. Гурова М.М., Циркунова В.В., Новикова В.П.Состояние микрофлоры кишечника у детей с хроническим гастродуоденитом в различные фазы течения заболевания. Вопросы детской диетологии. 2013;11(2):18-23.

19. Микробиота желудочно-кишечного тракта при хроническом гастрите. Барышникова Н.В., Гурова М.М., Иванова И.И., Кузьмина Д.А., Мельникова И.Ю., Новикова В.П., Осипов Г.А., Петровский А.Н., Самсонова М.В., Суворов А.Н., Суворова М.А., Успенский Ю.П., Цех О.М., Червинец В.М., Шабалов А.М.Под редакцией А.Н. Суворова, В.П. Новиковой, И.Ю. Мельниковой. Санкт-Петербург, 2014.

20. Гурова М.М., Новикова В.П.Состояние микроэлементного гомеостаза у детей с патологией верхних отделов пищеварительного тракта. Вопросы практической педиатрии. 2017. Т. 12. № 1. С. 7-12.

21. Новикова В.П., Волкова И.С., Воронцова Л.В.Влияние нутриентов на когнитивные функции. В сборнике: Знание пропедевтики - основа клинического мышления педиатра. сборник трудов, посвященный 80-летию проф. А.Я. Пучковой. Санкт-Петербург, 2015. С. 222-233.

22. Калинина Е.Ю., Аничков Н.М., Крылова Ю., Новикова В.П.Нейроэндокринные диффероны при дуоденитах различной этиологии у детей. Вопросы детской диетологии. 2017. Т. 15. № 2. С. 49-50.

23. Новикова В.П., Евстратова Ю.С., Козлов А.В.Применение газоанализатора «HELICOSENSE» для неинвазивной дыхательной диагностики хеликобактериоза. Методические рекомендации / СанктПетербург, 2005.

24. Акопян И.Г., Васильева Е.А., Евстратова Ю.С., Козлов А.В., Кукушкина И.А., Новикова В.П.Применение газоанализаторов серии «HELICOSENSE» для неинвазивной дыхательной диагностики хеликобактериоза. Методические рекомендации для врачей, руководителей лечебнопрофилактических учреждений / Санкт-Петербург, 2009.

25. Гурова М.М., Успенский Ю.П.Особенности вегетативной регуляции у детей подросткового возраста с хроническим гастродуоденитом в различные фазы течения заболевания. Российские медицинские вести. 2012. Т. 17. № 3. С. 58-64. 